\title{
Current evidence-based therapy does not restore plasma apelin level in phenotypically diverse chronic heart failure patients
}

\author{
Vinu Wilson ${ }^{1}$, Pankaj Prabhakar ${ }^{2}$, Sandeep Seth $^{3}$, Subir K. Maulik ${ }^{2}$
}

\begin{abstract}
${ }^{1}$ Department of Pharmacology, Sree Gokulam Medical College and Research Foundation,

Venjaramoodu,

Thiruvananthapuram, Kerala, India

${ }^{2}$ Department of Pharmacology,

${ }^{3}$ Department of Cardiology, All

India Institute of Medical

Sciences, Ansari Nagar, New

Delhi, India
\end{abstract}

Received: 21 November 2016

Accepted: 26 December 2016

*Correspondence to:

Dr. Vinu Wilson,

Email:

vinuwilson85@gmail.com

Copyright: (C) the author(s), publisher and licensee Medip Academy. This is an openaccess article distributed under the terms of the Creative Commons Attribution NonCommercial License, which permits unrestricted noncommercial use, distribution, and reproduction in any medium, provided the original work is properly cited.

\begin{abstract}
Background: Apelin, endogenous peptide acting through its receptor (APJ), is the most potent inotropic agent known to man. Plasma apelin and cardiac APJ mRNA levels rise in early stages of chronic heart failure (CHF) but fall later in decompensated CHF. The effect of current evidence-based management of CHF on plasma apelin level is not known. We estimated change in plasma apelin level in CHF patients of diverse phenotypes treated with standard pharmacotherapy and compared it with the corresponding change in left ventricular ejection fraction (LVEF), plasma brain natriuretic peptide (BNP) level and quality of life (QoL).

Methods: With ethical approval and written informed consent, venous blood samples were collected from $39 \mathrm{CHF}$ [dilated cardiomyopathy (DCM) $(n=21)$, restrictive cardiomyopathy $(\mathrm{RCM})(\mathrm{n}=9)$ and chronic constrictive pericarditis $(\mathrm{CCP})(\mathrm{n}=9)$ ] patients and 10 age-matched healthy controls, at baseline and after 12 weeks. Plasma apelin and BNP were estimated by competitive ELISA (RayBiotech Inc.) and an auto-analyzer (Triage, Allere Inc.), respectively. QoL was assessed using Kansas City Cardiomyopathy Questionnaire (KCCQ). Nonparametric tests were applied and $\mathrm{p}$-value $<0.05$ was considered significant. Results: Low LVEF, KCCQ score and high BNP levels were observed in all CHF patients compared to controls. Plasma apelin level was depressed in RCM and CCP patients compared to controls but not in DCM patients. These parameters did not change in any group after 3 months of standard pharmacotherapy.

Conclusions: Current evidence-based management of CHF does not restore the depressed apelin-APJ axis. New drugs are required for specifically modulating this promising therapeutic target in CHF.
\end{abstract}

Keywords: APJ, Adipokine, Heart failure, Neurohormone

\section{INTRODUCTION}

Chronic heart failure (CHF) is a morbid complication of cardiovascular diseases (CVD) of diverse etiologies. The prevalence of $\mathrm{CHF}$ is rising worldwide due to effective treatment of acute cardiovascular events resulting in improved rates of patient survival. The widely accepted neurohormonal model of chronic heart failure implicates several biological molecules as either favouring or opposing the pathological progression of the disease. One among these, the Brain natriuretic peptide (BNP), is now an established biomarker for diagnosis, risk stratification and monitoring of therapy in heart failure with reduced ejection fraction (HFrEF). ${ }^{1}$

Worldwide, research is being undertaken to identify novel biomarkers in CHF to facilitate early diagnosis, assessment of prognosis and possible therapeutic targeting. Apelin is one among several such endogenous substances with putative role in the pathophysiology of CVDs. $^{2}$ Discovered in 1998 as the endogenous ligand of then orphan APJ receptor, the apelin-APJ system is postulated to counterbalance the renin-angiotensinaldosterone system (RAAS) mediated adverse 
cardiovascular effects in CVDs. ${ }^{3-5}$ Apelin and its receptor are expressed in the human heart, blood vessels, lungs, brain, adipocytes and kidneys. ${ }^{6}$ Released from endothelial cells of cardiac blood vessels, it is the most potent endogenous inotropic agent known currently $\left(\mathrm{EC}_{50} 33\right.$ $\mathrm{pmol} / \mathrm{L}){ }^{7}$ The inotropic property of apelin is distinct because it is not associated with concomitant tachycardia or cardiac hypertrophy. ${ }^{5}$ Apelin also produces nitric oxide (NO)-dependent coronary and systemic vasodilatation, reducing both cardiac preload and afterload. ${ }^{2}$ It is endogenously degraded by the carboxypeptidase, angiotensin converting enzyme 2 (ACE2), which also catalyzes production of the vasodilatory peptide, angiotensin 1-7, from angiotensin II. $^{8}$ These properties strongly suggest a putative role for apelin in regulation of cardiovascular function in both health and disease. ${ }^{5}$

Several studies have documented changes in plasma apelin level in CVDs, though with some conflicting results. ${ }^{9}$ Plasma apelin is found to be reduced in several CVDs including chronic heart failure, essential hypertension, stable angina and myocardial infarction compared to healthy controls. ${ }^{9}$ In CHF, plasma apelin level seems to rise in early stages, but to decrease in later stages along with down-regulation of APJ receptors and both have been shown to recover following cardiac mechanical offloading with left ventricular assist devices. ${ }^{10,11}$ However, clinical studies have not monitored whether any change in plasma apelin level occurs in CHF patients being treated with evidence-based pharmacotherapy or following pericardiectomy in case of chronic constrictive pericarditis (CCP). In this study, we attempted to assess the response of plasma apelin level to current evidence-based therapy in CHF patients of different phenotypes.

\section{METHODS}

In this prospective, multiple arm, analytical observational study, CHF patients of diverse phenotypes were consecutively recruited from the heart failure clinic at the department of cardiology, with written informed consent. Ethical approval for the study was granted by the institutional ethics sub-committee (IESC/T-18/04.12.09). The study was registered with the clinical trial registry of India (2009/091/000935). CHF patients of either gender aged between 12 to 80 years, with $\geq$ class II NYHA symptoms and either reduced (HFrEF) (LVEF $\leq 40 \%)$ or preserved (HFpEF) (LVEF >40\%) left ventricular ejection fraction (LVEF) were consecutively recruited into the study. Subjects who were apparently healthy on clinical examination with normal laboratory investigation results and an unremarkable echocardiographic study were recruited as controls from among the relatives of the patients. Patients with history of an acute coronary syndrome within the previous one month, diabetes mellitus, severe or uncontrolled hypertension, obesity, hypercholesterolemia, hepatic or renal failure and pregnant or lactating women were excluded from the study.

\section{Primary outcome measure}

Change in plasma apelin level in CHF patients on evidence-based pharmacotherapy or following pericardiectomy (for CCP) over a period of 12 weeks.

\section{Secondary outcome measures}

(i) Comparison of plasma apelin level in CHF patients versus healthy controls at baseline and (ii) Find correlation, if any, between plasma apelin level versus plasma BNP level, LVEF and quality of life, over a period of 12 weeks.

\section{Clinical examination and laboratory investigations}

Screening of chronic heart failure patients for eligibility was done based on their clinical history, prior investigation and echocardiography reports not older than one month. Patients fulfilling inclusion and exclusion criteria and willing to participate in the study were asked to report after overnight fasting to the Clinical Pharmacology unit of department of Pharmacology. Patient information sheet was provided (in either Hindi or English language) to the patient and written informed consent was obtained. A blood sample $(5 \mathrm{~mL})$ was drawn from the antecubital vein using tourniquet for estimation of fasting blood glucose (FBG), serum total cholesterol, tests of renal (blood urea, serum creatinine) and liver (serum bilirubin, transaminases and serum alkaline phosphatase) function at the central laboratory.

Echocardiography was performed by author SS using adult transthoracic probe $(3.5 \mathrm{MHz})$. Left ventricular (LV) volumes and M-mode measurements (LV end systolic dimension, LV end diastolic dimension, fractional shortening) in parasternal short axis and apical (4 and 2 chamber) views were recorded and stored for offline analysis according to standard guidelines. ${ }^{12}$ Quality of life was assessed using the self-administered Kansas City Cardiomyopathy Questionnaire (KCCQ). ${ }^{13}$

\section{Estimation of plasma apelin}

A portion of the venous blood sample was centrifuged at $3000 \mathrm{rpm}$ at $4^{\circ} \mathrm{C}$ for 10 minutes. Plasma was separated and frozen in aliquots at $-70^{\circ} \mathrm{C}$ until analysis. Apelin was estimated in duplicate using the apelin-C terminus competitive enzyme linked immunoassay (ELISA) kit (RayBiotech Inc., USA), according to the manufacturers protocol. This assay targets the C-terminus of the 77amino acid apelin peptide and therefore detects all active forms of apelin including apelin-36, apelin-31, apelin-28 and apelin 13 .

\section{Estimation of plasma BNP}

Plasma BNP was estimated using a point of care device (Triage, Allere Inc., USA) following manufacturer's 
protocol. This device has been used validated previously in large clinical trials. ${ }^{14}$

\section{Statistical analysis}

Sample size of at least 8 patients in each group was calculated based on an expected difference of $10 \%$ in plasma apelin level due to standard therapy at an alpha level of 0.05 and a power of $90 \%$. However, it was decided to recruit all eligible patients providing consent into the study to improve its validity. Statistical analysis was done using STATA 11.2. Quantitative variables were reported as mean $\pm \mathrm{SD}$ (for normal distribution) or median with interquartile range (IQR) (for non-normal distribution) and categorical variables as counts (n) and frequencies $(\%)$. Comparison of baseline values of the groups versus controls was done using $t$ test for normally distributed data or Wilcoxon Rank-sum test for nonnormal data. Categorical variables were compared using Chi-square test or Fischer's exact test. Outcome measures were ccompared with respective baseline values using either paired $t$ test or Wilcoxon's signed rank test. A pvalue less than 0.05 was considered statistically significant.
A total of $39 \mathrm{CHF}$ patients and 10 normal controls were recruited into the study between February 2010 and August 2011. Among the CHF patients, echocardiography revealed that 23 had HFrEF (LVEF $\leq 40 \%$ ) and 16 had HFpEF (LVEF >40\%). The phenotypic profile of $\mathrm{CHF}$ patients was dilated cardiomyopathy (DCM) $(\mathrm{n}=21), \quad$ restrictive cardiomyopathy $(\mathrm{RCM})(\mathrm{n}=9)$ and chronic constrictive pericarditis $(\mathrm{CCP})(\mathrm{n}=9)$. The baseline characteristics of the study participants are shown in Table 1 . As expected, the systolic BP, diastolic BP and LVEF of CHF patients were lower compared to normal controls. Blood urea was elevated in CHF patients compared to controls without concomitant elevation of serum creatinine levels. Though serum bilirubin (in RCM and CCP patients) and SGOT (in CCP patients) were higher compared to controls, they were not significantly elevated to warrant specific treatment. Plasma BNP was elevated in all the three phenotypes of $\mathrm{CHF}$ patients compared to controls at baseline. Plasma apelin was significantly lower in RCM and CCP patients compared to controls. Quality of life, measured using overall summary score of KCCQ, was significantly depressed in all $\mathrm{CHF}$ patients compared to controls.

\section{RESULTS}

Table 1: Baseline characteristics of study subjects.

\begin{tabular}{|c|c|c|c|c|}
\hline Characteristic & $\begin{array}{l}\text { Normal } \\
\text { Controls } \\
(\mathbf{n}=\mathbf{1 0})\end{array}$ & $\begin{array}{l}\text { Dilated } \\
\text { cardiomyopathy } \\
\text { patients }(n=21)\end{array}$ & $\begin{array}{l}\text { Restrictive } \\
\text { cardiomyopathy } \\
\text { patients }(n=9)\end{array}$ & $\begin{array}{l}\text { Constrictive } \\
\text { pericarditis } \\
\text { patients }(n=9)\end{array}$ \\
\hline Age (years) & $37 \pm 12$ & $43 \pm 12$ & $35 \pm 14$ & $31 \pm 9$ \\
\hline Sex (m:f) & $7: 3$ & $12: 9$ & $4: 5$ & $6: 3$ \\
\hline BMI $\left(\mathrm{kg} / \mathrm{m}^{2}\right)$ & $22.8 \pm 2.9$ & $22.2 \pm 3.8$ & $20.6 \pm 4.5$ & $22.8 \pm 3.2$ \\
\hline Pulse rate (/min) & $79 \pm 7$ & $78 \pm 10$ & $70 \pm 11$ & $80 \pm 7$ \\
\hline Systolic BP (mm of $\mathrm{Hg}$ ) & $115 \pm 14$ & $102 \pm 7 * *$ & $100 \pm 6^{* *}$ & $115 \pm 14^{*}$ \\
\hline Diastolic BP (mm of $\mathrm{Hg}$ ) & $74 \pm 8$ & $67 \pm 5^{* *}$ & $64 \pm 8 * *$ & $69 \pm 5$ \\
\hline FBG (mg/dL) & $97 \pm 11$ & $105 \pm 25$ & $91 \pm 10$ & $95 \pm 10$ \\
\hline Blood urea (mg/dL) & $23 \pm 4$ & $34 \pm 13 * *$ & $33 \pm 11 *$ & $32 \pm 10 *$ \\
\hline S. Creatinine (mg/dL) & $1.0 \pm 0.1$ & $1.0 \pm 0.3$ & $1.0 \pm 0.2$ & $1.0 \pm 0.2$ \\
\hline S. Bilirubin (mg/dL) & $0.7 \pm 0.2$ & $0.9 \pm 0.3$ & $1.1 \pm 0.4^{*}$ & $1.1 \pm 0.3^{*}$ \\
\hline SGOT (IU/L) & $29 \pm 8$ & $28 \pm 7$ & $43 \pm 24$ & $43 \pm 16^{*}$ \\
\hline SGPT (IU/L) & $31 \pm 15$ & $25 \pm 11$ & $42 \pm 38$ & $39 \pm 20$ \\
\hline S. ALP (IU/L) & $116 \pm 21$ & $120 \pm 36$ & $132 \pm 49$ & $98 \pm 26$ \\
\hline T. Cholesterol (mg/dL) & $164 \pm 27$ & $171 \pm 43$ & $173 \pm 47$ & $171 \pm 27$ \\
\hline NYHA Class & NA & II $(n=21)$ & II $(n=9)$ & II $(n=8)$, III $(n=1)$ \\
\hline LVEF $(\%)$ & $63 \pm 3$ & $27 \pm 8 * *$ & $44 \pm 13 * *$ & $55 \pm 3 * *$ \\
\hline KCCQ clinical summary score (\%) & $100 \pm 0$ & $74 \pm 16^{* *}$ & $67 \pm 20 * *$ & $54 \pm 26 * *$ \\
\hline Plasma BNP (pg/mL) & $6(5,10)$ & $87(17,365)^{* *}$ & $520(276,1085)^{* *}$ & $172(92,257)^{* *}$ \\
\hline Plasma Apelin (pg/mL) & $570(415,680)$ & $450(230,620)$ & $300(205,590)^{*}$ & $380(230,420)^{*}$ \\
\hline Loop diuretics (n) & NA & 21 & 8 & 5 \\
\hline ACEIs (n) & NA & 12 & 3 & 0 \\
\hline ARBs (n) & NA & $9^{\#}$ & 0 & 0 \\
\hline Beta blockers (n) & NA & $17^{\#}$ & 2 & 0 \\
\hline Digoxin (n) & NA & 12 & 5 & 1 \\
\hline Spironolactone(n) & NA & 18 & 8 & 5 \\
\hline
\end{tabular}

*p $<0.05$ compared to control, **p $<0.01$ compared to control. ${ }^{\#} \mathrm{p}<0.05$ compared to RCM patients. 
The prescription profile of drugs in the CHF patients indicated that significantly higher proportion of DCM patients were on Angiotensin II type 1 receptor blockers (ARBs) and beta adrenergic blockers compared to RCM patients (Table 1). The patients of CCP were on the least number of drugs in consonance with their distinct pathophysiology. Change in the dose of the standard drugs prescribed was not necessitated in any of the CHF patients over the observation period of 12 weeks. However, there was no change in LVEF, plasma BNP, plasma apelin or quality of life of $\mathrm{CHF}$ patients on follow-up after 12 weeks (Table 2). In the sole CCP patient who underwent elective pericardial resection, plasma apelin and BNP levels improved from $220 \mathrm{pg} / \mathrm{mL}$ and $91.7 \mathrm{pg} / \mathrm{mL}$ to $320 \mathrm{pg} / \mathrm{mL}$ and $20.2 \mathrm{pg} / \mathrm{mL}$ after 12 weeks, respectively. No association was found between plasma apelin levels and LVEF, KCCQ score or plasma BNP levels.

Table 2: Outcome measures after 12 weeks of standard therapy.

\begin{tabular}{|c|c|c|c|}
\hline $\begin{array}{l}\text { Outcome } \\
\text { measure }\end{array}$ & $\begin{array}{l}\text { Time- } \\
\text { point }\end{array}$ & $\begin{array}{l}\text { Dilated } \\
\text { cardiomyop- } \\
\text { athy patients } \\
(\mathbf{n}=21)\end{array}$ & $\begin{array}{l}\text { Restrictive } \\
\text { cardiomyo- } \\
\text { pathy patients } \\
(n=9)\end{array}$ \\
\hline \multirow{2}{*}{$\begin{array}{l}\text { LVEF } \\
(\%)\end{array}$} & Baseline & $27 \pm 8$ & $44 \pm 13$ \\
\hline & 12 weeks & $28 \pm 8$ & $45 \pm 13$ \\
\hline \multirow{2}{*}{$\begin{array}{l}\text { KCCQ } \\
\text { clinical } \\
\text { summary } \\
\text { score }(\%)\end{array}$} & Baseline & $74 \pm 16$ & $69(52,87)$ \\
\hline & 12 weeks & $76 \pm 23$ & $64(35,81)$ \\
\hline \multirow{2}{*}{$\begin{array}{l}\text { Plasma } \\
\text { BNP } \\
(\mathrm{pg} / \mathrm{mL})\end{array}$} & Baseline & $87(17,365)$ & $520(276,1085)$ \\
\hline & 12 weeks & $119(14,237)$ & $752(490,2070)$ \\
\hline \multirow{2}{*}{$\begin{array}{l}\text { Plasma } \\
\text { Apelin } \\
(\mathrm{pg} / \mathrm{mL})\end{array}$} & Baseline & $\begin{array}{l}450(230, \\
620)\end{array}$ & $300(205,590)$ \\
\hline & 12 weeks & $\begin{array}{l}380(275, \\
550)\end{array}$ & $360(240,390)$ \\
\hline
\end{tabular}

\section{DISCUSSION}

Our study has for the first time shown that plasma apelin levels are reduced in two distinct phenotypes of chronic heart failure viz. restrictive cardiomyopathy (RCM) and chronic constrictive pericarditis (CCP) compared to normal controls. However, they are not restored to normal levels by standard pharmacotherapy over 12 weeks.

The clinical diagnosis of CHF in our patients was confirmed by elevated plasma BNP and significantly reduced LVEF and KCCQ score compared to normal controls. BNP is now widely accepted as a reliable biomarker for diagnosis of decompensated heart failure. ${ }^{15}$ It has been recommended as a rapid bedside test to differentiate between underlying primary cardiac versus pulmonary disease presenting as acute dyspnea to emergency departments. ${ }^{15,16}$ It also aids in establishing severity of $\mathrm{CHF}$ and in predicting their long term prognosis. ${ }^{15}$ LVEF, a surrogate marker of cardiac output, is routinely measured to assess ventricular function and monitor disease progression in CHF patients. However, several studies have shown that LVEF poorly correlates with functional capacity and Quality of Life (QoL) reported by patients. ${ }^{17,18}$ Therefore, clinical studies of CHF have increasingly incorporated patient reported QoL measures such as the KCCQ score for an assessment of patient's perspectives regarding therapy. Moreover, improvement in scores on QoL questionnaires have been shown to be associated with improvements in patient survival. $^{19,20}$

Elevated blood urea nitrogen (BUN) observed in the patients may be attributed to reduced renal perfusion in CHF. Though blood urea was elevated, preservation of serum creatinine within clinically normal limits indicated that the patients were not in overt renal failure. Some studies have pointed out that BUN elevation in CHF patients might also be due to increased renal urea reabsorption from distal tubules by non-osmotically released arginine vasopressin (AVP) in worsening $\mathrm{CHF}^{21,22}$ Assessment of renal function was important because both plasma apelin and BNP levels are known to be elevated in renal failure. ${ }^{16,23}$ Elevated serum bilirubin and transaminase levels in CCP and RCM patients could be attributed to hepatic dysfunction secondary to elevated central venous pressure. ${ }^{24}$

The drugs prescribed in the patients were in consonance with the current evidence-based treatment guidelines which advocate a Renin-angiotensin-aldosterone system (RAAS) inhibitor (ACEI / ARB) and a beta adrenergic blocker as standard of care in symptomatic HFrEF patients. ${ }^{15}$ However, evidence regarding the possible benefits of these drugs in HFpEF patients is equivocal, thereby making management of comorbidities the major therapeutic goal. ${ }^{15}$ This difference in pharmacotherapy reflected in our study as lower proportion of RCM patients were prescribed an ARB and beta blocker compared to DCM patients. On the other hand, the CCP patients were on minimal pharmacotherapy since the definitive treatment is pericardial resection, which was undergone by a lone patient during the study period.

Plasma apelin level was found to be depressed in RCM and CCP while not in DCM patients. Circulating apelin is predominantly synthesized from atria in healthy individuals. $^{11}$ In both RCM and CCP, ventricular relaxation is impaired leading to elevated atrial pressure and atrial dilatation. Mechanical stretch has been shown to decrease apelin gene expression in cultured neonatal rat ventricular myocytes. ${ }^{7}$ We postulate that stretching of atrial myocytes may analogously decrease atrial apelin synthesis in RCM and CCP patients. In fact, APJ is now recognized as a dual receptor for both apelin and mechanical stretch, with their relative activities biasing its signaling. ${ }^{25}$ While apelin signals through APJ in $\mathrm{Ga}_{\mathrm{i}^{-}}$ dependent manner for its cardioprotective effects, 
mechanical stretch induces pathologic cardiac hypertrophy by activating APJ dependent extracellular signal-regulated kinase (ERK) phosphorylation and simultaneously depresses apelin signalling by promoting $\beta$-arrestin mediated APJ internalization. ${ }^{25}$ Moreover, pulmonary hypertension, a common complication in these patients, has also been reported to be associated with low serum apelin levels for less understood reasons. $^{26}$

It has been shown in both animal and human studies that increased synthesis of apelin accompanies cardiomyocyte hypertrophy in response to hemodynamic stress and that either exhaustion of apelin synthetic machinery or its excessive degradation heralds cardiovascular decompensation. ${ }^{27}$ Though apelin can override stretchinduced APJ activation, there is lack of compensatory activation of apelin expression in APJ knockout or wild type mice in response to hemodynamic stress. ${ }^{25}$ This suggests that mechanical stretch acting through different mechanosensors viz. APJ and ATII type 1 receptor induces pathologic cardiac hypertrophy with minimal compensatory up-regulation of apelin synthesis. ${ }^{25,28}$ The development of dilated ventricles instead of hypertrophy in DCM patients may be related to altered mechanoreceptor signaling or the protective effects of preserved apelin level observed in our study.

The lack of change in LVEF, plasma BNP level or KCCQ score in DCM and RCM patients over 12 weeks of standard pharmacotherapy may seem surprising. It could be due to previous treatment with standard drugs received by these patients referred to our tertiary care hospital so that many of them could have already achieved maximum possible therapeutic benefits of these drugs. Further, the duration of follow-up in our study might have been inadequate to detect slow developing changes in the clinical status of patients. The fact that most of the clinical trials of current heart failure treatments involved follow-up of 4-12 months supports this speculation. ${ }^{29,30}$

In the same vein, the short period of observation in our study may have been inadequate for development of change in plasma apelin level. However, an alternative hypothesis could be explored. Upregulation of ACE2 in failing hearts may prevent compensatory rise in plasma apelin levels. ${ }^{31}$ This may happen even in presence of ACEIs which suppress ACE activity but not that of ACE2. Moreover, ACEIs and ARBs have been shown to upregulate ACE2 gene expression after myocardial infarction. ${ }^{32}$ However, apelin and ACE2 are thought to synergistically antagonize detrimental effects of RAAS signaling. Apelin has been shown to positively regulate ACE2 expression while product of apelin catalysis by ACE2 has been shown to retain its biological effects. ${ }^{33,34}$ Moreover, Ang 1-7, produced from ATII by ACE2, acts on Mas receptor to induce cardioprotective effects. ${ }^{33}$ Recently, efforts are being made to develop apelin analogues resistant to ACE2 metabolism as potential drugs in $\mathrm{CHF}^{35}$

Apelin-APJ axis is thought to be an exciting therapeutic target in CHF because it is a potent positive inotrope which offloads the heart while preventing pathologic cardiac hypertrophy induced by sustained neurohormonal activation. It antagonizes Ang II induced ATII type 1 receptor activation by allosteric trans-inhibition besides opposing the deleterious effects of sustained RAAS activation in $\mathrm{CHF}^{36}$ Though its plasma levels and cardiac expression are increased in early heart failure, its signaling is impaired in late stages by currently unclear mechanisms. A clinical study of intravenous apelin infusion in healthy volunteers and CHF patients has shown encouraging results. ${ }^{37}$ Development of pegylated apelin, nano-liposomal apelin and a G-protein biased APJ agonist recently have strengthened the hope for a therapeutic breakthrough in $\mathrm{CHF}^{38-40}$ Drugs which indirectly accentuate apelin signaling by inhibiting its degradation could theoretically be beneficial in $\mathrm{CHF}$ patients.

\section{CONCLUSION}

Current evidence-based management of diverse CHF phenotypes does not restore the depressed apelin-APJ axis signaling. New drugs are required for specifically modulating this promising therapeutic target in CHF.

\section{ACKNOWLEDGEMENTS}

This work was supported by Indian Council of Medical Research (I.C.M.R.) grant no. 3/2/2010-2/PG-ThesisMPD-13.

Funding: Indian Council of Medical Research (I.C.M.R.) Conflict of interest: None declared

Ethical approval: The study was approved by the Institutional Ethics Sub-Committee (IESC/T18/04.12.09).

\section{REFERENCES}

1. Gardner RS, McDonagh TA. The reign of the natriuretic peptides in patients with heart failure continues. Biomark Med. 2008;2(5):437-9.

2. Chandrasekaran B, Dar O, McDonagh T. The role of apelin in cardiovascular function and heart failure. Eur J Heart Fail J Work Group Heart Fail Eur Soc Cardiol. 2008;10(8):725-32.

3. O'Dowd BF, Heiber M, Chan A, Heng HH, Tsui LC, Kennedy JL, et al. A human gene that shows identity with the gene encoding the angiotensin receptor is located on chromosome 11. Gene. 1993;136(12):355-60.

4. Tatemoto K, Hosoya M, Habata Y, Fujii R, Kakegawa T, Zou MX, et al. Isolation and characterization of a novel endogenous peptide 
ligand for the human APJ receptor. Biochem Biophys Res Commun. 1998;251(2):471-6.

5. Barnes G, Japp AG, Newby DE. Translational promise of the apelin-APJ system. Heart Br Card Soc. 2010;96(13):1011-6.

6. Medhurst AD, Jennings CA, Robbins MJ, Davis RP, Ellis C, Winborn KY, et al. Pharmacological and immunohistochemical characterization of the APJ receptor and its endogenous ligand apelin. J Neurochem. 2003;84(5):1162-72.

7. Szokodi I, Tavi P, Földes G, Voutilainen-Myllylä S, Ilves $\mathrm{M}$, Tokola $\mathrm{H}$, et al. Apelin, the novel endogenous ligand of the orphan receptor APJ, regulates cardiac contractility. Circ Res. 2002;91(5):434-40.

8. Danilczyk U, Penninger JM. Angiotensin-converting enzyme II in the heart and the kidney. Circ Res. 2006;98(4):463-71.

9. Pitkin SL, Maguire JJ, Bonner TI, Davenport AP. International Union of Basic and Clinical Pharmacology. LXXIV. Apelin receptor nomenclature, distribution, pharmacology, and function. Pharmacol Rev. 2010;62(3):331-42.

10. Chen MM, Ashley EA, Deng DXF, Tsalenko A, Deng A, Tabibiazar R, et al. Novel role for the potent endogenous inotrope apelin in human cardiac dysfunction. Circulation. 2003;108(12):1432-9.

11. Földes G, Horkay F, Szokodi I, Vuolteenaho O, Ilves M, Lindstedt KA, et al. Circulating and cardiac levels of apelin, the novel ligand of the orphan receptor $\mathrm{APJ}$, in patients with heart failure. Biochem Biophys Res Commun. 2003;308(3):480-5.

12. Lang RM, Bierig M, Devereux RB, Flachskampf FA, Foster E, Pellikka PA, et al. Recommendations for chamber quantification: a report from the American Society of Echocardiography's Guidelines and Standards Committee and the Chamber Quantification Writing Group, developed in conjunction with the European Association of Echocardiography, a branch of the European Society of Cardiology. J Am Soc Echocardiogr Off Publ Am Soc Echocardiogr. 2005;18(12):1440-63.

13. Green CP, Porter CB, Bresnahan DR, Spertus JA. Development and evaluation of the Kansas City Cardiomyopathy Questionnaire: a new health status measure for heart failure. J Am Coll Cardiol. 2000;35(5):1245-55.

14. Lubien E, DeMaria A, Krishnaswamy P, Clopton P, Koon J, Kazanegra R, et al. Utility of B-natriuretic peptide in detecting diastolic dysfunction: comparison with Doppler velocity recordings. Circulation. 2002;105(5):595-601.

15. Yancy CW, Jessup M, Bozkurt B, Butler J, Casey $\mathrm{DE}$, Drazner $\mathrm{MH}$, et al. ACCF/AHA guideline for the management of heart failure: a report of the American College of Cardiology Foundation/American Heart Association Task Force on Practice Guidelines. J Am Coll Cardiol. 2013;62(16):e147-239.
16. Palazzuoli A, Gallotta M, Quatrini I, Nuti R. Natriuretic peptides (BNP and NT-proBNP): measurement and relevance in heart failure. Vasc Health Risk Manag. 2010;6:411-8.

17. McNamara RL, Austin BA, Wang Y, Smith GL, Vaccarine V, Krumholz HM. Systolic Function as a Predictor of Mortality and Quality of Life in Longterm Survivors with Heart Failure. Clin Cardiol. 2008;31(3):119-24.

18. Hoekstra T, Lesman-Leegte I, van Veldhuisen DJ, Sanderman R, Jaarsma T. Quality of life is impaired similarly in heart failure patients with preserved and reduced ejection fraction. Eur $\mathbf{J}$ Heart Fail. 2011;13(9):1013-8.

19. Zuluaga MC, Guallar-Castillón P, López-García E, Banegas JR, Conde-Herrera M, Olcoz-Chiva M, et al. Generic and disease-specific quality of life as a predictor of long-term mortality in heart failure. Eur $\mathbf{J}$ Heart Fail. 2010;12(12):1372-8.

20. Hoekstra T, Jaarsma T, van Veldhuisen DJ, Hillege HL, Sanderman R, Lesman-Leegte I. Quality of life and survival in patients with heart failure. Eur J Heart Fail. 2013;15(1):94-102.

21. Schrier RW. Blood Urea Nitrogen and Serum Creatinine Not Married in Heart Failure. Circ Heart Fail. 2008;1(1):2-5.

22. Filippatos G, Rossi J, Lloyd-Jones DM, Stough WG, Ouyang J, Shin DD, et al. Prognostic value of blood urea nitrogen in patients hospitalized with worsening heart failure: insights from the Acute and Chronic Therapeutic Impact of a Vasopressin Antagonist in Chronic Heart Failure (ACTIV in CHF) study. J Card Fail. 2007;13(5):360-4.

23. Pitkin SL, Maguire JJ, Kuc RE, Davenport AP. Modulation of the apelin/APJ system in heart failure and atherosclerosis in man. $\mathrm{Br} \mathrm{J}$ Pharmacol. 2010;160(7):1785-95.

24. Samsky MD, Patel CB, DeWald TA, Smith AD, Felker GM, Rogers JG, et al. Cardiohepatic Interactions in Heart FailureAn Overview and Clinical Implications. J Am Coll Cardiol. 2013;61(24):2397-405.

25. Scimia MC, Hurtado C, Ray S, Metzler S, Wei K, Wang J, et al. APJ acts as a dual receptor in cardiac hypertrophy. Nature. 2012;488(7411):394-8.

26. Chandra SM, Razavi H, Kim J, Agrawal R, Kundu RK, de Jesus Perez V, et al. Disruption of the apelinAPJ system worsens hypoxia-induced pulmonary hypertension. Arterioscler Thromb Vasc Biol. 2011;31(4):814-20.

27. Japp AG, Newby DE. The apelin-APJ system in heart failure: pathophysiologic relevance and therapeutic potential. Biochem Pharmacol. 2008;75(10):1882-92.

28. Zou Y, Akazawa H, Qin Y, Sano M, Takano H, Minamino $\mathrm{T}$, et al. Mechanical stress activates angiotensin II type 1 receptor without the involvement of angiotensin II. Nat Cell Biol. 2004;6(6):499-506.

29. Greenberg B, Quinones MA, Koilpillai C, Limacher M, Shindler D, Benedict C, et al. Effects of long-term 
enalapril therapy on cardiac structure and function in patients with left ventricular dysfunction. Results of the SOLVD echocardiography substudy. Circulation. 1995;91(10):2573-81.

30. Hjalmarson A, Goldstein S, Fagerberg B, Wedel H, Waagstein F, Kjekshus J, et al. Effects of controlledrelease metoprolol on total mortality, hospitalizations, and well-being in patients with heart failure: the Metoprolol CR/XL Randomized Intervention Trial in congestive heart failure (MERIT-HF). MERIT-HF Study Group. JAMA. 2000;283(10):1295-302.

31. Goulter AB, Goddard MJ, Allen JC, Clark KL. ACE2 gene expression is up-regulated in the human failing heart. BMC Med. 2004;2:19.

32. Ishiyama Y, Gallagher PE, Averill DB, Tallant EA, Brosnihan KB, Ferrario CM. Upregulation of Angiotensin-Converting Enzyme 2 After Myocardial Infarction by Blockade of Angiotensin II Receptors. Hypertension. 2004;43(5):970-6.

33. Sato $T$, Suzuki $T$, Watanabe $H$, Kadowaki A, Fukamizu A, Liu PP, et al. Apelin is a positive regulator of ACE2 in failing hearts. J Clin Invest. 2013;123(12):5203-11.

34. Yang P, Kuc RE, Maguire JJ, Brame AL, Morrell NW, Davenport AP. Cellular Localisation and Functions of the ACE2 Metabolite of (Pyr1) apelin13. Proc Physiol Soc. 2013;Proc 37 $7^{\text {th }}$ IUPS. Available at http://www.physoc.org/proceedings/abstract/Proc\%2 037th\%20IUPSPCA092

35. Wang W, McKinnie SMK, Farhan M, Paul M, McDonald $\mathrm{T}$, McLean $\mathrm{B}$, et al. Angiotensin-
Converting Enzyme 2 Metabolizes and Partially Inactivates Pyr-Apelin-13 and Apelin-17: Physiological Effects in the Cardiovascular System. Hypertension. 2016;68:365-77.

36. Siddiquee K, Hampton J, McAnally D, May L, Smith L. The apelin receptor inhibits the angiotensin II type 1 receptor via allosteric trans-inhibition. $\mathrm{Br} \mathrm{J}$ Pharmacol. 2013;168(5):1104-17.

37. Barnes GD, Alam S, Carter G, Pedersen CM, Lee KM, Hubbard TJ, et al. Sustained Cardiovascular Actions of APJ Agonism During Renin-Angiotensin System Activation and in Patients with Heart Failure. Circ Heart Fail. 2013;6:482-91.

38. Jia ZQ, Hou L, Leger A, Wu I, Kudej AB, Stefano J, et al. Cardiovascular effects of a PEGylated apelin. Peptides. 2012;38(1):181-8.

39. Brame AL, Maguire JJ, Yang P, Dyson A, Torella R, Cheriyan J, et al. Design, characterization, and firstin-human study of the vascular actions of a novel biased apelin receptor agonist. Hypertension. 2015;65(4):834-40.

40. Serpooshan V, Sivanesan S, Huang X, Mahmoudi M, Malkovskiy AV, Zhao M, et al. [Pyr1]-Apelin-13 deliveries via nano-liposomal encapsulation attenuates pressure overload-induced cardiac dysfunction. Biomaterials. 2015;37:289-98.

Cite this article as: Wilson V, Prabhakar P, Seth S, Maulik SK. Current evidence-based therapy does not restore plasma apelin level in phenotypically diverse chronic heart failure patients. Int $\mathrm{J}$ Basic Clin Pharmacol 2017:6:316-22. 